\title{
Two Different Processes to Obtain Antimicrobial Packaging Containing Natural Oils
}

\author{
Andrea Carolina Valderrama Solano • \\ Cecilia de Rojas Gante
}

Received: 7 December 2010 / Accepted: 3 June 2011 / Published online: 23 June 2011

(C) The Author(s) 2011. This article is published with open access at Springerlink.com

\begin{abstract}
In this study, antimicrobial packaging materials were developed by incorporating known concentrations $(w / w)$ of essentials oils of oregano (Origanum vulgare) and thyme (Thymus vulgaris) into low-density polyethylene (LDPE), suitable for use as food packaging, via two different methods: ionizing treatment and directly by extrusion. The mechanical, barrier, and antimicrobial properties of the packaging were evaluated against the following foodborne pathogens: Salmonella typhimurium, Listeria monocytogenes, and Escherichia coli O157:H7. The results demonstrate that films developed by extrusion incorporating $4 \%(w / w)$ of essential oils had a higher inhibitory effect than those obtained using the ionizing treatment. The packaging developed by extrusion containing $1 \%(w / w)$ showed a positive inhibitory effect, while those obtained by the ionizing treatment had no inhibitory effect against any of the test microorganisms. The incorporation of essential oils on the LDPE films generated a plasticizer effect, whereas the ones obtained by means of ionizing treatment did significantly affect the barrier properties of the films. The results of this study showed that plantderived essential oils could be incorporated in active films for food packaging.
\end{abstract}

Keywords Antimicrobial packaging · Essential oils . Low-density polyethylene

\footnotetext{
A. C. Valderrama Solano $\cdot$ C. de Rojas Gante $(\triangle)$ Department of Biotechnology and Food Engineering, Tecnológico de Monterrey, Campus Monterrey, Ave. Eugenio Garza Sada 2501 Sur, Col. Tecnológico, C.P. 64849 Monterrey, Nuevo León, Mexico e-mail: crd@itesm.mx
}

\section{Introduction}

Food packaging has been traditionally defined as a passive barrier that delays environment effects on food products (Brody 2002; López-Rubio et al. 2004). However, trends in current research involve the development of packaging materials that can positively interact with the environment and food, playing an active role in preservation. To date, active packaging is a novel food biopreservation technique for extending the shelf life of food products (Barros Velazquez 2011). Antimicrobial packaging, an innovative concept, can be defined as a kind of active packaging in which the package, the product, and the environment interact to reduce, inhibit, or retard the growth rate of microorganisms (Suppakul et al. 2008). In these technologies, researchers are developing food packaging materials such as synthetic films (Suppakul et al. 2006, 2008; López et al. 2007) and edible films (Natrajan and Sheldon 2000a; Ouattara et al. 2000; Jagannath et al. 2006; Kim et al. 2006; Seydim and Sarikus 2006; Rojas-Grau et al. 2006; Campos et al. 2010) with antimicrobial properties. Polymers are effective vehicles for the active substance (López-Rubio et al. 2004), giving the possibility to incorporate different antimicrobial additives. A first example is low-density polyethylene (LDPE), which may incorporate imazalil (Weng and Hotchkiss 1992; Vartiainen et al. 2003), organic acids (Dobias et al. 2000), nisin (Scannell et al. 2000; Natrajan and Sheldon 2000b), hexamethylenetetramine (Devlieghere et al. 2000a), or food preservatives (Devlieghere et al. 2000b). A second example is polyethylene (PE), which may be coated with an antimicrobial peptide (Miltz et al. 2006). A third example is hydroxypropylmethylcellulose, which may incorporate nisin by cross-linking (Sebti et al. 2003). 
Although many studies have demonstrated the antimicrobial effect of essential oils and their active compounds against a broad spectrum of pathogenic bacteria in food (Burt and Reinders 2003; Di Pascua et al. 2005; Carson et al. 2006), there are very few publications that discuss their incorporation as additives in polymeric plastic films (Ha et al. 2001; Suppakul et al. 2006, 2008; López et al. 2007). Given that the US Food and Drug Administration categorizes natural extracts such as essential oils (EOs) and their constituents as generally recognized as safe, packaging manufacturers and demanding consumers consider the incorporation of these natural extracts in plastic films an appealing way of avoiding microbial food spoilage (Nerín et al. 2008). The current study aims to develop antimicrobial LDPE films using two incorporation methods, to determine the antimicrobial activity of these films against selected pathogenic microorganism and to assess the effect of incorporation of oregano and thyme essential oils on mechanical and barrier properties in the active films.

\section{Materials and Methods}

\section{Materials}

Essential oils of thyme (Thymus vulgaris) and oregano (Origanum vulgare) were used as the antimicrobial agents. The EOs were obtained from Primavera Life (Sulzberg, Germany) and were selected for their high antimicrobial activity and wide availability. The polymer used in these studies was LDPE (PEMEX 20020X, Monterrey, Mexico); attractive characteristics of this polymer include ease of processing, chemically inertness, and low cost.

\section{Development of Antimicrobial Films}

The EOs were incorporated into polyolefin films using two processing methods that would not compromise the antimicrobial potency of the oils: an ionizing treatment and extrusion.

\section{Method 1-Ionizing Treatment}

In this method, the EOs were incorporated by deposition on the surface of the film after surface modification using an ionizing treatment. Initially, LDPE films were produced using a single screw extruder (Kilion Extruders Inc, Verona, NJ, USA) with an L/D ratio screw of 24:1 and an operating speed of $30 \mathrm{rpm}$. The temperature profile from the first barrel zone to the die was $140 / 160 / 190 / 190{ }^{\circ} \mathrm{C}$. The film surface was ionized by electronic radiation using the Laboratory Corona Treater model BD-20AC (ElectroTechnic Products, Inc., IL, USA). The wire electrode was passed back and forth approximately $2.5 \mathrm{~cm}$ above each film surface for $2 \mathrm{~min}$ at high frequency of $4-5 \mathrm{MHz}$. After the film surface was ionized by electronic radiation, the films were characterized with a sessile drop contact angle measurement in order to determine the change in surface hydrophilicity Then, samples of the treated films $(5 \times 5 \mathrm{~cm})$ were taken randomly from an area of $1 \mathrm{~m}^{2}$ and a volume of each essential oil was placed on each sample. The samples were placed in an incubator $\left(30 \pm 2{ }^{\circ} \mathrm{C}\right)$ to evaporate the solvents. LDPE films incorporating $1 \%$ and $4 \%(w / w)$ of EOs and control films were produced without EO.

\section{Method 2-Extrusion}

The EOs were preblended with polymer resin LDPE into a master batch (Brabender Instruments, Inc., South Hackensack, NJ, USA). Two hundred fifty grams of resin was added to the mixer with $40 \mathrm{ml}$ of $\mathrm{EO}$ at $110{ }^{\circ} \mathrm{C}$ and $50 \mathrm{rpm}$ for $30 \mathrm{~min}$. The preblended oil resin was then ground in a knife mill to produce 2-mm fragments and finally incorporated with virgin resin pellets in a single screw extruder (Kilion Extruders Inc.) with an L/D ratio screw of $24: 1$ and an operating speed of $30 \mathrm{rpm}$. The temperature profile from the fed zone to the die was $120 / 155 / 175 / 175{ }^{\circ} \mathrm{C}$. The extrusion and master batch temperatures of the LDPE $\left(120-190{ }^{\circ} \mathrm{C}\right)$ were changed to protect the active oil compounds from oxidation based on the thermal study of EOs (DTA, data not shown). LDPE films incorporating $1 \%$ and $4 \%(w / w)$ of EOs and control films without EOs were produced.

The antimicrobial films developed with both methods were immediately wrapped in aluminum foil to minimize the loss of the antimicrobial agent by evaporation and were then stored at room temperature for up to 1 week prior to testing. An average of 10 measurements were taken at different points on the film sample using a digital micrometer (Digimatic Outside Micrometer, Mitutoyo, Japan) to measure the thickness of the sample.

\section{Contact Angle Measurements}

After the film surface was ionized by electronic radiation (method 1, mentioned above), the films were characterized with a sessile drop contact angle measurement in order to determine the change in surface hydrophilicity. Contact angle measurements were obtained using a goniometer (Ramé-Hart, Mountain Lakes, NJ, USA). For these measurements, water, a standard solution for a $32^{\circ}$ contact angle, thyme EO, and oregano EO were used as test solutions. A drop of test solution $(5 \mu \mathrm{l})$ from a microsyringe (HamiltonBonaduz, GR, Switzerland) was placed on the surface of the modified films. The sample stage and CCD camera position were adjusted so that the image of the drop was clearly obtained on the computer monitor, and the image 
was captured $5 \mathrm{~s}$ after depositing the drop. The angle formed between the liquid drop and the film was recorded as the contact angle. Reported contact angle values are an average of five measurements.

\section{Determination of Antimicrobial Effect of Active Films}

The antimicrobial activity of active films was determined quantitatively using the agar plate diffusion method. The zone of inhibition on solid media was used to determine the antimicrobial effects of active films against Escherichia coli 0157:H7, Salmonella typhimurium, and Listeria monocytogenes. From each bacterial dispersion $\left(10^{6} \mathrm{CFU} / \mathrm{ml}\right), 100 \mu \mathrm{l}$ was spread onto an agar plate medium. Then, each antimicrobial film $(2 \times 2 \mathrm{~cm})$ was placed over the surface of the agar plate medium. The plates were incubated at $37^{\circ} \mathrm{C}$ for $24 \mathrm{~h}$ in an appropriate incubation chamber. The antimicrobial activity was observed as a zone of inhibition of the targeted microorganisms around the active film, and the diameter of the zone was measured with a digital micrometer (Digimatic Outside Micrometer, Mitutoyo). All tests were performed in triplicate. LDPE films without essential oils were included as controls.

\section{Tensile Properties of the Films}

A standard method D882-02 (ASTM 2002) was used to measure the tensile properties of the films. Films were cut into strips with a test dimension of $169 \times 19 \mathrm{~mm}$ according to the standard method D638-08 (ASTM 2008). All films were conditioned for $48 \mathrm{~h}$ at $23 \pm 2{ }^{\circ} \mathrm{C}$ and $50 \pm 2 \% \mathrm{RH}$ before testing. The strips were mounted and clamped with pneumatic grips on a universal testing machine (United Calibration Corp. and United Testing Systems, Inc., California, USA) with a $100-\mathrm{N}$ load cell. The initial gauge length was set to $100 \mathrm{~mm}$, and films were stretched using a crosshead speed of $10 \mathrm{~mm} / \mathrm{min}$. The parameters of tensile strength and elongation at break were determined. Measurements were performed on five replicates.

\section{Oxygen Transmission Rate of the Films}

Measurements were performed with an Ox-Tran 2/21 Oxygen Transmission Rate System (Mocon, Modern Controls Inc., Minneapolis, MN, USA) according to the standard method D3985-05 (ASTM 2005). Oxygen transmission rates (OTR) were determined at $23{ }^{\circ} \mathrm{C}$ and $0 \% \mathrm{RH}$.

Water Vapor Transmission Rate of the Films

A Permatran-W 3/31 Permeation Analysis System (Mocon, Modern Controls Inc.) was used to the measure water vapor transmission rate (WVTR) according to the standard method F-1249-06 (ASTM 2006). Tests were carried out at $37.8{ }^{\circ} \mathrm{C}$ temperature and $100 \% \mathrm{RH}$.

\section{Statistical Analysis}

Data points were presented as the mean of the measured values. The data were subjected to an analysis of variance and the Turkey test at the 0.05 level of significance (Xlstat 2009).

\section{Results and Discussion}

The activation of LDPE films with thyme and oregano EOs was performed using two different methods. LDPE films with thicknesses of $23 \pm 3 \mu \mathrm{m}$ were prepared using the ionizing treatment and LDPE films with thickness of $27.5 \pm$ $3.5 \mu \mathrm{m}$ using the extrusion method. To incorporate and protect the essential oils, the standard extrusion conditions of LDPE films $\left(120-190^{\circ} \mathrm{C}\right)$ were modified. Reductions of $20{ }^{\circ} \mathrm{C}$ in the first barrel zone and $15^{\circ} \mathrm{C}$ in the other zones were obtained without compromising the structural and mechanical integrity of the film.

\section{Contact Angle Measurements of Ionized Films}

The measurements of contact angle were studied in order to test the effectiveness of ionizing radiation and their impact on the surface properties of LDPE film. The ionizing treatment altered the PE surface from hydrophobic to relatively hydrophilic by introducing mainly oxygen (Yamamoto et al. 2011). The contact angle between liquid-solid interfaces is a good indicator of adsorption because it increases the capacity of the liquid to spread, thereby decreasing the contact angle (Rubin 2004). Therefore, liquids with a lower contact angle will have a greater capacity to spread and penetrate a solid surface.

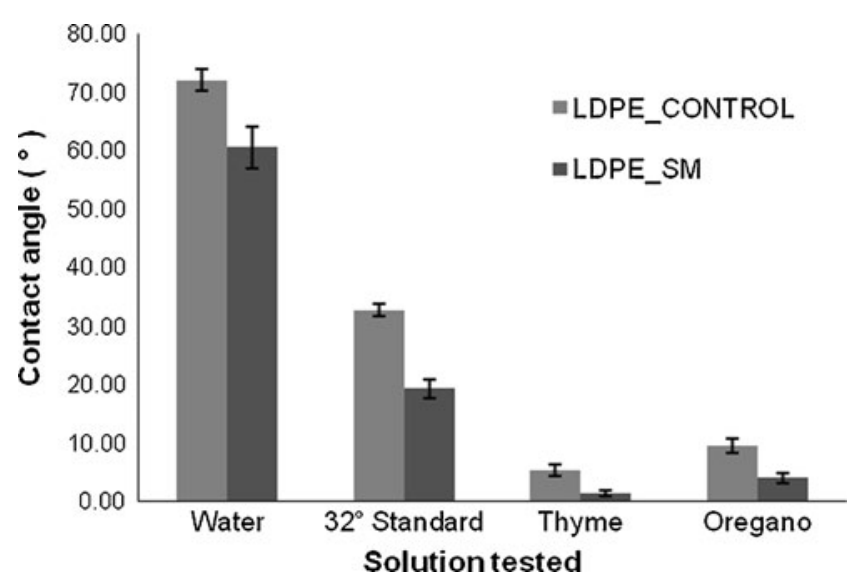

Fig. 1 Contact angle of surface-modified LDPE films by means of ionizing method. $S M$ surface modified 
- Salmonella typhimurium aEscherichiacoli 0157:H7

- Listeria monocytogenes

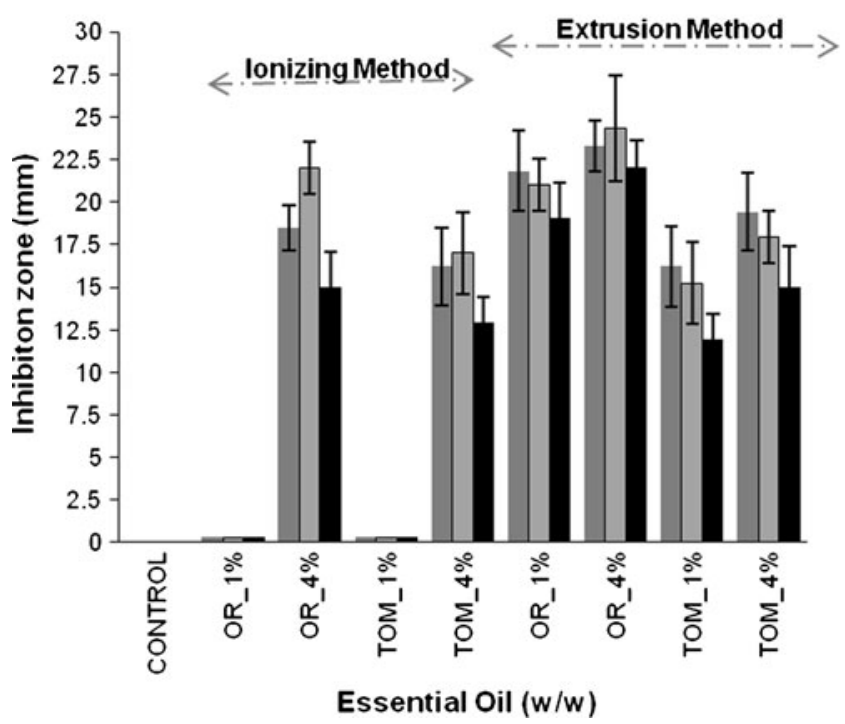

Fig. 2 Antimicrobial activity of LDPE films incorporating thyme and oregano essential oils against E. coli 0157:H7, S. typhimurium, and $L$. monocytogenes

The measured contact angles for each solution tested are illustrated in Fig. 1. All tested solutions showed a reduction in contact angle. Water, which initially had the highest contact angle due to the hydrophobic nature of polyolefin films, showed a $15.97 \%$ reduction of its contact angle. The contact angle of a standard solution for a $32^{\circ}$ contact angle showed a reduction of $41.22 \%$. Initially, the oregano and thyme EOs showed significantly lower contact angles compared to water and the standard solution due to the polyolefin's high affinity for fatty substances. However, the contact angles of the oils also showed the largest percentage reductions. Reductions of $76.19 \%$ and $57.89 \%$ were observed in the contact angles of oregano and thyme EOs, respectively. The results showed that the ionization treatment modified the film surface and increased the surface energy, resulting in a chemically active surface that increased the essential oil's effectiveness and ease of adhesion.

\section{Antimicrobial Activity Assay of Active Films}

Figure 2 shows the antimicrobial activity of LDPE active films against $E$. coli 0157:H7, S. typhimurium, and $L$. monocytogenes. As expected, in all cases, the films without essential oils did not show antimicrobial activity against any microorganisms. The ionization and extrusion methods both yielded positive results, although the resulting antimicrobial activity was significantly different in each case.

LDPE active films developed using the ionizing method incorporating $4 \%(w / w)$ of EOs were effective against all tested microorganisms (Fig. 2). However, the ionized films incorporating $1 \%(w / w)$ of EOs showed no antimicrobial activity. This effect may be due to the lower concentration of oil, which does not allow effective adhesion of the oil to the film surface. Although the ionization method showed no activity at low concentrations, it would be worthwhile to explore ways of improving it (varying power, time, and electrode type). On the other hand, the inhibition tests were conducted with microorganisms at concentrations well above those that are normally involved in food deterioration.

The LDPE active films developed using the extrusion method incorporating $1 \%$ and $4 \%(w / w)$ of thyme and oregano

Fig. 3 Representative picture of inhibitory zones of LDPE films incorporated with $4 \%(w / w)$ oregano essential oil compared to control against $E$. coli 0157 : H7, S. typhimurium, and $L$. monocytogenes

\begin{tabular}{|c|c|c|c|}
\hline BACTERIAL & CONTROL & $\begin{array}{c}\text { LDPE+ OREGANO 4\% } \\
\text { EXTRUSION } \\
\text { METHOD }\end{array}$ & $\begin{array}{c}\text { LDPE + OREGANO } \\
\text { 4\% } \\
\text { IONIZING METHOD }\end{array}$ \\
\hline $\begin{array}{c}\text { Escherichia coli } \\
0157: H 7\end{array}$ & & & \\
\hline $\begin{array}{c}\text { Salmonella } \\
\text { typhimurium }\end{array}$ & & & \\
\hline $\begin{array}{c}\text { Listeria } \\
\text { monocytogenes }\end{array}$ & & & \\
\hline
\end{tabular}


Table 1 Effect of the incorporation of essential oils on mechanical properties of LDPE films

\begin{tabular}{|c|c|c|c|c|}
\hline \multirow[t]{2}{*}{ Incorporation method } & \multirow[t]{2}{*}{ Type of polymer } & \multicolumn{3}{|l|}{ Properties } \\
\hline & & Thickness $(\mu \mathrm{m})$ & Tensile strength $\left(\mathrm{kg} / \mathrm{mm}^{2}\right)$ & Elongation at break $(\%)$ \\
\hline- & LDPE (control) & $0.023 \pm 0.003 \mathrm{a}$ & $1.319 \pm 0.107 \mathrm{a}$ & $171 \pm 22 b$ \\
\hline \multirow[t]{4}{*}{ Ionizing method } & LDPE $+1 \%$ oregano & $0.024 \pm 0.003 \mathrm{a}$ & $1.227 \pm 0.121 \mathrm{a}$ & $178 \pm 28 \mathrm{ab}$ \\
\hline & LDPE $+4 \%$ oregano & $0.022 \pm 0.004 \mathrm{a}$ & $1.357 \pm 0.121 \mathrm{a}$ & $174 \pm 12 \mathrm{ab}$ \\
\hline & LDPE $+1 \%$ thyme & $0.022 \pm 0.003 \mathrm{a}$ & $1.322 \pm 0.129 \mathrm{a}$ & $180 \pm 15 \mathrm{ab}$ \\
\hline & LDPE $+4 \%$ thyme & $0.025 \pm 0.002 \mathrm{a}$ & $1.180 \pm 0.124 \mathrm{a}$ & $172 \pm 25 \mathrm{ab}$ \\
\hline \multirow[t]{4}{*}{ Extrusion method } & LDPE $+1 \%$ oregano & $0.023 \pm 0.002 \mathrm{a}$ & $1.282 \pm 0.082 \mathrm{a}$ & $180 \pm 17 \mathrm{ab}$ \\
\hline & LDPE $+4 \%$ oregano & $0.024 \pm 0.002 \mathrm{a}$ & $0.832 \pm 0.085 b$ & $221 \pm 11 \mathrm{a}$ \\
\hline & LDPE $+1 \%$ Thyme & $0.023 \pm 0.002 \mathrm{a}$ & $1.202 \pm 0.124 \mathrm{a}$ & $177 \pm 21 \mathrm{ab}$ \\
\hline & LDPE $+4 \%$ thyme & $0.023 \pm 0.002 \mathrm{a}$ & $0.791 \pm 0.063 b$ & $225 \pm 21 \mathrm{a}$ \\
\hline
\end{tabular}

Thickness $(N=10)$, tensile strength $(N=5)$ and elongation $(N=5)$ data are mean values \pm standard deviation. Means in same column with different lowercase letters are significantly different $(p<0.05)$

$L D P E$ low-density polyethylene

EOs showed antimicrobial activity against all tested microorganism (Fig. 2). Other authors also reported the effectiveness of LDPE films incorporating essential oils (propolis, clove, basil, oregano, and cinnamon) at concentrations from $0.5 \%$ to $5 \%(w / w)$ (Hong et al. 2000; López et al. 2007; Suppakul et al. 2008) with different activation procedures than those presented in this study. These results demonstrate the powerful utility of LDPE films as antimicrobial packaging materials when they are formulated with EOs.

LDPE active films developed by extrusion showed a significantly higher inhibition than films developed using the ionizing method. The results suggest that the extrusion method allowed a better incorporation of the active compounds on the polymer. Figure 3 shows pictures representing the zones of inhibition of antimicrobial films incorporated with oregano EO against tested microorganisms.

There were also differences in the antimicrobial activity as a function of the EO incorporated; the films containing oregano oil were found to be more effective than those containing thyme oil, as illustrated in Fig. 2. The interactions of EOs have crucial effects on the antimicrobial activity of active films. Ting and
Deibel (1991), Smith-Palmer et al. (1998), Hammer et al. (1999), and Burt and Reinders (2003) all observed strong antibacterial properties of oregano essential oil when directly applied against E. coli O157:H7, L. monocytogenes, S. typhimurium, Staphylococcus aureus, Candida albicans, Aeromonas sobria, and Pseudomonas aeruginosa. These authors found that the inhibitory effect of oregano was due to the high concentration of phenolic compounds such as carvacrol and thyme. Carvacrol and thyme (the major components of oregano and thyme EOs) are able to disintegrate the outer membrane of gram-negative bacteria, releasing lipopolysaccharides and increasing the permeability of the cytoplasmic membrane to ATP (Burt 2004).

Effect of Incorporation of EOs on the Mechanical and Barrier Properties of LDPE Plastic Films

\section{Mechanical Properties of Antimicrobial LDPE Films}

Tensile strength, elongation, and thickness were measured in order to study the effect of EO incorporation on the

Table 2 Effect of the incorporation of essential oils on the barrier properties of LDPE films

\begin{tabular}{lllll}
\hline Incorporation method & Type of polymer & \multicolumn{2}{l}{ Properties } & \\
\cline { 3 - 5 } & & Thickness $(\mu \mathrm{m})$ & WVTR $\left(\mathrm{g} / \mathrm{m}^{2} / \mathrm{day}\right)$ & $\mathrm{OTR}\left(\mathrm{ml} / \mathrm{m}^{2} / \mathrm{day}\right)$ \\
\hline \multirow{3}{*}{ Ionizing method } & LDPE (control) & $0.023 \pm 0.003$ & $13.8 \pm 0.3 \mathrm{a}$ & $6,658.7 \pm 66.5 \mathrm{~b}$ \\
& LDPE $+1 \%$ oregano & $0.024 \pm 0.003$ & $13.6 \pm 0.3 \mathrm{a}$ & $6,791.7 \pm 39.6 \mathrm{~b}$ \\
Extrusion method & LDPE $+4 \%$ oregano & $0.022 \pm 0.004$ & $11.8 \pm 0.7 \mathrm{~b}$ & $6,213.6 \pm 14 \mathrm{c}$ \\
& LDPE $+1 \%$ oregano & $0.023 \pm 0.002$ & $10.2 \pm 0.4 \mathrm{~b}$ & $5,070.3 \pm 5.5 \mathrm{c}$ \\
\hline
\end{tabular}

Data are expressed as mean \pm standard deviation $(N=4)$.Means in same column with different lowercase letters are significantly different $(p<0.05)$ $L D P E$ low-density polyethylene, WVTR water vapor transmission rate, OTR oxygen transmission rate 
mechanical properties of films. Mechanical properties of films with and without EOs are shown in Table 1. No significant differences were observed between the thicknesses of films with and without EOs. Incorporating any of the EOs in the plastic films developed using the ionizing method did not affect the mechanical properties of films. However, the active films developed using the extrusion method showed a significant reduction in tensile strength and an increase in elongation. These results suggest that incorporating EOs in LDPE films using the extrusion method produces a plasticizing effect on the films. This effect manifested as a $9.28 \%$ reduction in the tensile strength and a $7.75 \%$ increase in the percentage elongation of the films. Similar results were reported by Dobias et al. (2000). They found statistically significant differences between the mechanical properties of films without antimicrobial agents and those with different agents at concentrations of $0.5 \%(w / w)$ and $1 \%(w / w)$, and found that the tensile and sealing strengths were lower in all samples.

\section{Barrier Properties of Antimicrobial LDPE-Based Films}

Only the LDPE films incorporated with oregano essential oil were evaluated, because these active films exhibited the greatest antimicrobial effect using both methods of incorporation. Table 2 shows OTR and WVTR values of the active films. In the ionized films, incorporating $1 \% w / w$ of oregano EO had no effect on the WVTR and OTR properties. However, a slight decrease in these properties was observed after incorporating $4 \% w / w$ oregano EO. In the extrusion method, incorporating oregano EO significantly affected the WVTR and OTR properties of the films. The films incorporating 1\% $(w / w)$ of oregano EO showed a reduction in the OTR and WVTR; and those with 4\% (w/w) showed an unexpected increase in the OTR property. These results suggest that in the extrusion method, the oregano EO $(1 \% w / w)$ was solubilized and could migrate to the amorphous region of the polymeric structure due to the nature of the oils. However, the amorphous region was saturated after the addition of $4 \%(w / w)$ of oregano EO, and the addition of further oregano EO interfered with the polymer-polymer interactions, resulting in the increased in the OTR property of the LDPE films.

\section{Conclusions}

The direct addition of oregano and thyme EOs into LDPE polymer matrices using two simple methods was possible. The antimicrobial films developed showed antimicrobial activity against food pathogens such as $S$. typhimurium, $L$. monocytogenes, and E. coli O157:H7. Antimicrobial films incorporating $4 \%(w / w)$ of the EOs developed using the extrusion method showed a greater inhibitory effect than those obtained using the ionizing method. The incorporation of essential oils into LDPE films changed some characteristics of the packaging material slightly, such as the mechanical and barrier properties. Incorporating EOs using the extrusion method significantly affected the mechanical and barrier properties of the films, while the incorporation using the ionizing method significantly affected only the barrier properties.

Acknowledgments This work was supported by grant 12786-2005 provided by National Council on Science and Technology (CONACYT) of Mexico. The authors would like to give thanks to Mexican center of applied chemistry (Ph.D. Francisco Javier Rodriguez G), department of plastic transformation processing.

Open Access This article is distributed under the terms of the Creative Commons Attribution Noncommercial License which permits any noncommercial use, distribution, and reproduction in any medium, provided the original author(s) and source are credited.

\section{References}

ASTM. (2002). Standard test method for tensile properties of thin plastic sheeting. D882-02. In: Annual book of American Standard Testing Methods. Philadelphia, PA: ASTM.

ASTM (2005) Standard test method for oxygen gas transmission rate through plastic film and sheeting using a coulometric sensor. D3985-05. In Annual book of American Standard Testing Methods. Philadelphia, PA: ASTM.

ASTM. (2006). Standard test method for water vapor transmission rate through plastic film and sheeting using a modulated infrared sensor. F1249-06. In Annual book of American Standard Testing Methods. Philadelphia, PA: ASTM.

ASTM. (2008). Standard test method for tensile properties of plastics. D638-08. In Annual book of American Standard Testing Methods. Philadelphia, PA: ASTM

Brody, A. (2002). Active and intelligent packaging: the saga continues. Food Technology, 56, 65-66.

Barros Velazquez, J. (2011). Innovations in food technology special issue. Food and Bioprocess Technology, doi:10.1007/s11947-011-0576-9.

Burt, S. (2004). Essential oil: their antibacterial properties and potential applications in food-a review. International Journal of Food Microbiology, 94, 223-253.

Burt, S., \& Reinders, R. (2003). Antibacterial activity of selected plant essential oil against Escherichia coli O157:H7. Letters in Applied Microbiology, 36, 162-167.

Campos, C., Gerschenson, L., \& Flores, S. (2010). Development of edible films and coatings with antimicrobial activity. Food and Bioprocess Technology, doi:10.1007/s11947-010-0434-1.

Carson, C., Hammer, K., \& Riley, T. (2006). Mechanism of action of Melaleuca alternifolia (tea tree) oil on Staphylococcus aureus determined by time-kill, lysis, leakage and salt tolerance assay and electron microscopy. Clinical Microbiology Reviews, 19, 50-62.

Devlieghere, F., Vermeiren, L., Jacobs, M., \& Debevere, J. (2000). The effectiveness of hexamethylenetetramine incorporated plastic for the active packaging of foods. Packaging Technology \& Science, 13, 117-121.

Devlieghere, F., Vermeiren, L., Bockstal, A., \& Debevere, J. (2000). Study of antimicrobial activity of a food packaging material containing potassium sorbate. Acta Alimentaria, 29, 137-148. 
Di Pascua, R., De Feo, V., Villani, F., \& Mauriello, G. (2005). In vitro antimicrobial activity of essential oils from Mediterranean Apiaceae, Verbenaceae and Lamiaceae against foodborne pathogens and spoilage bacteria. Annals of Microbiology, 55, 139-143.

Dobias, J., Chudackova, K., Voldrich, M., \& Marek, M. (2000). Properties of polyethylene films with incorporated benzoic anhydride and/or ethyl and propyl esters of 4-hydroxybenzoic acid and their suitability for food packaging. Food Additives and Contaminants, 17, 1047-1053.

Ha, J., Kim, Y., \& Lee, D. (2001). Multilayered antimicrobial polyethylene films applied to the packaging of ground beef. Packaging Technology and Science, 15, 55-62.

Hammer, K., Carson, C., \& Riley, T. (1999). Antimicrobial activity of essential oils and other plant extracts. Journal of Applied Microbiology, 86, 985-990.

Hong, S., Park, J., \& Kim, D. (2000). Antimicrobial and physical properties of food packaging films incorporated with some natural compounds. Journal of Science and Biotechnology, 9, $38-42$.

Jagannath, J., Nanjappa, C., Gupta, D., \& Bawa, A. (2006). Studies on the stability of an edible film and its use for the preservation of carrot (Daucus carota). Internation Journal of Food Science Technology, 41, 498-506.

Kim, K. M., Lee, B. Y., \& Kim, Y. T. (2006). Development of antimicrobial edible film incorporated with green tea extract. Food Science and Biotechnology, 15, 478-481.

López, P., Sanchez, C., Batle, R., \& Nerín, C. (2007). Development of flexible antimicrobial films using essentials oils as active agents. Journal of Agricultural and Food Chemistry, 55, 8814-8824.

López-Rubio, A., Almenar, E., Hernandez-Muñoz, P., Lagarrón, J., Catalá, R., \& Gavara, R. (2004). Overview of active polymerbased packaging technologies for food applications. Food Reviews International, 20, 357-387.

Miltz, J., Rydlo, T., Mor, A., \& Polyakov, V. (2006). Potency evaluation of a dermaseptin S4 derivate for antimicrobial food packaging applications. Packaging Technology Science, 19, $345-354$.

Natrajan, N., \& Sheldon, B. (2000a). Inhibition of Salmonella on poultry skin using protein and polysacharide-base films containing nisin formulation. Journal of Food Protection, 63, $1268-1272$.

Natrajan, N., \& Sheldon, B. (2000b). Efficacy of nisin-coated polymer films to inactivate Salmonella typhimurium on fresh broiler skin. Journal of Food Protection, 63, 1189-1196.
Nerín, C., Tovar, L., \& Salafranca, J. (2008). Behaviour of a new antioxidant active films versus oxidizable model compound. Journal of Food Engineering, 84, 313-320.

Ouattara, B., Simard, R., Piette, G., Begin, A., \& Holley, R. (2000). Diffusion of acetic and propionic acids from chitosan-based antimicrobial packaging films. Journal of Food Science, 65, 768-773.

Rojas-Grau, M., Avena-Bustillos, R., \& Friedman, M. (2006). Mechanical barrier and antimicrobial properties of apple pureedible films containing plant essential oils. Journal of Agricultural Food Chemistry, 54, 9262-9267.

Rubin, I. (2004). Materiales Plásticos, Propiedades y Aplicaciones. México: Edit. Imusa, S.A.

Scannell, A., Hill, C., Ross, R., Marx, S., Hartmeier, W., \& Arendt, E. (2000). Development of bioactive food packaging materials using immobilized bacteriocins lacticin 3147 and Nisaplin. International Journal of Food Microbiology, 2-3, 241-249.

Sebti, I., Delves-Broughton, J., \& Coma, V. (2003). Physicochemical properties and bioactivity of nisin-containing cross-linked hydroxypropylmethylcellulose films. Journal of Agricultural Food Chemistry, 51, 6468-6474.

Seydim, A., \& Sarikus, G. (2006). Antimicrobial activity of whey protein based edible films incorporated with oregano, rosemary and garlic essential oils. Food Research International, 39, 639-644.

Smith-Palmer, A., Stewart, J., \& Fyfe, L. (1998). Antimicrobial properties of plant essential oils and essences against five important food-borne pathogens. Letters in Food Microbiology, 26, 118-122.

Suppakul, P., Miltz, J., Sonneveld, K., \& Bigger, S. (2006). Characterization of antimicrobial films containing basil extracts. Packaging Technology and Science, 19, 259-268.

Suppakul, P., Sonneveld, K., Biggen, S., \& Miltz, J. (2008). Efficacy of polyethylene-based antimicrobial films containing principal constituents of basil. LWT-Food Science and Technology, 41, 779-788.

Ting, W., \& Deibel, K. (1991). Sensitivity of Listeria monocytogenes to spices at two temperatures. Journal of Food Safety, 12, 129-137.

Vartiainen, J., Skytta, E., \& Ahvenainen, R. (2003). Antimicrobial and barrier properties of LDPE films containing Imazil and EDTA. Journal of Plastic Film and Sheeting, 19, 249-261.

Weng, Y., \& Hotchkiss, J. (1992). Inhibition of surface moulds on cheese by polyethylene film containing the antimycotic imazalil. Journal of Food Protection, 55, 367-369.

Yamamoto, K., Kimura, T., Nam, K., Funamoto, S., Ito, Y., Shiba, K., et al. (2011). Synthetic polymer-tissue adhesion using an ultrasonic scalpel. Surgical Endoscopy, 25, 1270-1275. 